\title{
Influence of Xylenol Orange Dye on Optical, Thermal, Dielectric, Laser Damage Threshold and Mechanical Properties of L-Alanine Thiourea (LATU) Single Crystals
}

\author{
R. Kannan \\ Department of Physics \\ Presidency College, Chennai- \\ 600005, Tamilnadu, India
}

\author{
D. Jayaraman \\ Department of Physics \\ Presidency College, Chennai- \\ 600005, Tamilnadu, India
}

\author{
S. Aravindhan \\ Department of Physics \\ Presidency College, Chennai- \\ 600005, Tamilnadu, India
}

\begin{abstract}
Bulk single crystals of pure and xylenol orange dye (XO) admixtured L-Alanine Thiourea (LATU) were grown by slow evaporation technique. The cell parameters and crystallinity of pure and dye admixtured LATU crystals were confirmed by single crystal, powder X-ray diffraction and high resolution $\mathrm{X}$-ray diffraction analyses. The functional groups present in the crystals were confirmed by FTIR analysis. The UV-visNIR transmission studies show the optical transparency in the entire visible region of xylenol orange dye admixtured LATU crystal. The laser damage threshold value significantly enhanced for dye admixtured crystal in comparison with pure LATU crystal. The crystals were further subjected to other important characterizations such as dielectric measurement, micro hardness, thermal and NLO studies. The relative SHG efficiency of xylenol admixtured LATU crystal was found to be 1.64 times higher than that of pure LATU crystal.
\end{abstract}

\section{Keywords}

Slow evaporation technique, powder X-ray diffraction, dielectric properties, nonlinear optical study.

\section{INTRODUCTION}

Nonlinear optical (NLO) crystals are a key material for the development of laser science and technology because there is almost only this kind of materials that have functions to change frequency of laser beam and modulate it in amplitude and phase. It may be said that lasers could not be used so widely in modern science and technology as they have been today, without NLO crystals. Development of NLO crystals with better linear optical (LO) and NLO properties, wider spectral transmission and phase-matching range in particular is obviously essential for further widening the application field of lasers. That is why many scientists working in the field today are still putting in great effort to search for new NLO crystals, even more than four decades after the invention of the laser. Among organic crystals for nonlinear optics (NLO) applications, amino acids display specific features of interest [1], such as molecular chirality which secures acentric crystallographic structures, absence of strongly conjugated bonds, leading to wide transparency ranges in the visible and UV spectral regions and zwitterionic nature of the molecule, which favours crystal hardness [2]. Further to that, amino acids can be used as chiral auxiliaries for nitro-aromatics and other donor-acceptor molecules with large hyperpolarizability [3]. The growth of large single crystals of amino acids has been little investigated so far, even as regards the simplest acentric member of the family, L -Alanine $\left(\mathrm{CH}_{3} \mathrm{CHNH}_{2} \mathrm{COOH}\right)$. L-Alanine was first crystallized by BERNAL and later by SIMPSON et al. and DESTRO et al., who refined the structure $(\mathrm{a}=6.032 \AA, \mathrm{b}=12.343 \AA, \mathrm{c}=$ $5.784 \AA ; \alpha=\beta=\gamma=90^{\circ}$ ) and assigned it the $\mathrm{P} 2{ }_{1} 2_{1} 2_{1}$ space group [4-6]. In both cases, very small crystals were grown, unsuitable for optical investigations. In the recent years, complex of thiourea NLO crystals have attracted among the researchers [7] due to its flexibility in synthesis of a new complex. Thiourea ligand has both $\mathrm{S}$ and $\mathrm{N}$ donors; it can be coordinated either through $\mathrm{S}$ or $\mathrm{N}$ with few amino acids and forms a stable organic complex. Thiourea is an organic matrix modifier due to its large dipole moment and its ability to form hydrogen bonds [8]. A Thiourea crystal finds widespread use as frequency doublers in laser applications and was studied in great detail. Improvement in the quality of the Thiourea crystals and the performance of this crystal-based device can be realized with suitable dopants. To analyse the influence of dye based dopant on the centro symmetric Thiourea molecule, when combined with amino acids yields non-centrosymmetric complexes, which possess in general good nonlinear optical properties [9]. Some of the nonlinear crystals of the amino acid complexes of Thiourea reported are glycine Thiourea [10], L-Histidine Thiourea [11] and Methylene blue admixtured L-Alanine Thiourea [12]. Among these the second harmonic generation efficiency (SHG) of glycine Thiourea crystal was 0.5 times that of KDP crystal, the SHG efficiency of L-Histidine Thiourea crystal 4.1 times that of KDP crystal and Methylene blue admixtured LAlanine Thiourea crystal 1.56 times that of KDP crystal. Many researchers have worked on dye admixtured potassium dihydrogen phosphate and potassium acid phthalate nonlinear optical crystals in order to improve their nonlinear response $[13,14]$. Xylenol orange [3, 3' bis [N, N'- Di(carboxymethyl) - aminomethyl - O - cresolsulphone - phthalein tetrasodium salt] (XO), a heterocyclic species which belongs to the acidic class of dyes. This anionic dye, which is stable and water soluble with an absorption peak at $577 \mathrm{~nm}$, was chosen as a representative species for this study [15]. The xylenol orange (XO) molecules possess electro active nitrogen, oxygen, sulphur atoms and aromatic rings and electron rich para quinanoid aromatic rings. The structure of xylenol orange molecule is shown in Fig. 1.

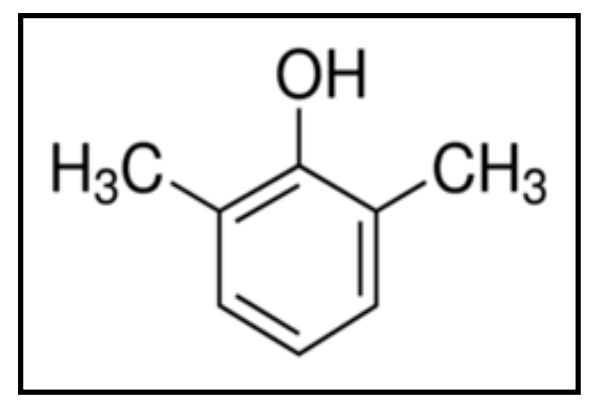

Fig. 1. Structure of Xylenol Orange 
It is soluble in water and used for dying and indicator. Xylenol orange dye stuff retains the acid-base properties of cresol red and displayed metal indicator properties even in acid solution ( $\mathrm{pH} 3.5$ ). Acidic solutions of the indicators are coloured lemon yellow and those of the thiourea complexes are intensely orange [16]. Hence the admixture of xylenol orange dye in LATU crystals is expected to have high second order nonlinearity. In the present investigation, a comparative study on the growth, structural, UV-vis-NIR transmission, thermal, dielectric, mechanical, non-linear optical and laser damage threshold studies of pure and xylenol orange dye admixtured LATU crystals have been reported.

\section{EXPERIMENTAL PROCEDURE}

L-Alanine Thiourea (LATU) was synthesized by dissolving high purity Thiourea and L-Alanine in the equimolar ratio in aqueous medium. Thiourea was first dissolved in Millipore water and then L-Alanine was added with continuous stirring for about 2 hours using a magnetic stirrer at $50{ }^{\circ} \mathrm{C}$. The product was obtained as per the following reaction.

$$
\begin{aligned}
\mathrm{H}_{2} \mathrm{~N}-\mathrm{CS}- & \mathrm{NH}_{2}+\mathrm{CH}_{3} \mathrm{CHNH}_{2} \mathrm{COOH} \\
& \rightarrow \mathrm{H}_{2} \mathrm{~N}-\mathrm{CS} \\
& -\mathrm{NH}_{3}{ }^{-} \mathrm{CH}_{3} \mathrm{CHNH}_{2} \mathrm{COO}^{+}
\end{aligned}
$$

(Thiourea + L-Alanine $\rightarrow$ L-Alanine Thiourea)

The impurity content of L-Alanine Thiourea (LATU) was minimized by the process of recrystallization. The $\mathrm{pH}$ value of the solution was about 7.24. The $\mathrm{pH}$ value was adjusted to 3.5 by adding few drops concentrated hydrochloric acid [17]. Then it was filtered using Whatmann filter paper and the filtered solution was kept in a borosil beaker covered with an aluminium foil and the solvent was allowed to evaporate at room temperature. As a result of slow evaporation, after 30 days, colourless and transparent LATU crystal with dimensions of $12 \times 3 \times 3 \mathrm{~mm}^{3}$ was obtained. The same experimental procedure was adopted for the synthesis of xylenol orange dye $(5 \mathrm{~mol} \%)$ admixtured LATU salt. The seed crystal with perfect shape and free from macro defects was used for the growth of dye admixtured LATU crystal by slow evaporation method. The photographs of LATU and xylenol orange dye admixtured LATU (XOLATU) crystals are shown in Fig. 2 and Fig. 3.

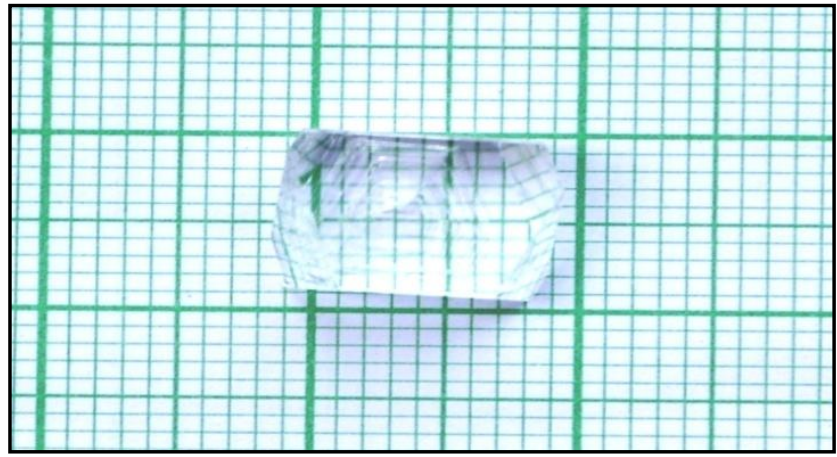

Fig. 2. Grown LATU crystal

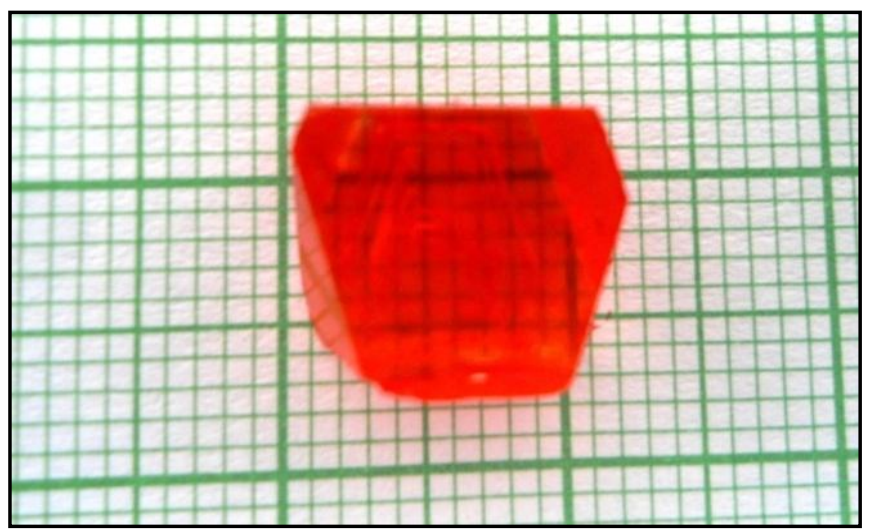

Fig. 3. Grown XOLATU crystal

\section{RESULT AND DISCUSSION}

\subsection{Single Crystal XRD Analysis}

The single crystal XRD analysis of LATU and xylenol orange dye admixtured LATU (XOLATU) crystals were carried out using MESSRS ENRAF NONIUS CAD4-F, single X-ray diffractometer with $\operatorname{MoK} \alpha(\lambda=0.71073 \AA)$ radiation. The lattice parameters of LATU and XOLATU crystals obtained from single crystal XRD analysis are presented in Table 1. The single crystal XRD study reveals that the presence of dopant has not altered the basic structure of the LATU crystal. The lattice parameter values of xylenol orange dye admixtured crystal may be attributed to the lattice strain in the

\begin{tabular}{|c|c|c|c|c|c|c|}
\hline S. No. & $\begin{array}{c}\text { Crystal } \\
\text { name }\end{array}$ & $\begin{array}{l}\text { Axial lengths } \\
\text { of unit cell } \\
(a, b \text { and } c)\end{array}$ & $\begin{array}{c}\text { Inter axial } \\
\text { angles } \\
(\alpha, \beta \text { and } \gamma)\end{array}$ & Volume & Crystal system & Space group \\
\hline 01. & LATU & $\begin{array}{l}\mathrm{a}=9.6312 \AA \\
\mathrm{b}=5.6136 \AA \\
\mathrm{c}=9.4142 \AA\end{array}$ & $\begin{array}{l}\alpha=\gamma=90^{\circ} \\
\beta=109.48^{\circ}\end{array}$ & $508.98 \AA^{3}$ & Monoclinic & $\mathrm{P} 2_{1}$ \\
\hline 02. & XOLATU & $\begin{array}{l}\mathrm{a}=9.6410 \AA \\
\mathrm{b}=5.6250 \AA \\
\mathrm{c}=9.4220 \AA\end{array}$ & $\begin{array}{l}\alpha=\gamma=90^{\circ} \\
\beta=109.48^{\circ}\end{array}$ & $510.96 \AA^{3}$ & Monoclinic & $\mathrm{P} 2_{1}$ \\
\hline
\end{tabular}
grown crystals due to the incorporation of the dye dopant.

Table 1. Comparison of lattice parameters of LATU and XOLATU 


\subsection{Powder XRD Analysis}

The grown crystals of LATU and XOLATU were crushed into fine powder and powder X-ray diffraction analysis has been carried out using Rich Seifert X-ray diffractometer. The $\mathrm{X}$-axis of graph is $2 \theta$. The $\mathrm{Y}$-axis gives the intensity in arbitrary units. The samples were subjected to intense $\mathrm{X}$-ray of wavelength $1.5406 \AA(\mathrm{CuK} \alpha)$ at a scan speed of $1 \%$ minute to obtain lattice parameters. The Miller indices (hkl), dspacing and diffraction angle $(2 \theta)$ are summarized for LATU and XOLATU are shown in Table 2 and Table 3 with the help of RexCell program and their powder diffractograms are shown in Fig. 4 \& Fig. 5.

Table 2. Miller indices, $d$-spacing and $2 \theta$-values of L-Alanine Thiourea (LATU) single crystal determined from powder XRD analysis using RexCell software.

\begin{tabular}{|c|c|c|c|c|c|c|c|}
\hline S. No. & $\mathbf{h}$ & $\mathbf{k}$ & $\mathbf{l}$ & $\begin{array}{c}\mathbf{d}(\mathbf{o b s}) \\
\left(\mathbf{A}^{\circ}\right)\end{array}$ & $\begin{array}{c}\mathbf{d}(\mathbf{c a l c}) \\
\left(\mathbf{A}^{\circ}\right)\end{array}$ & $\begin{array}{c}\mathbf{2 \theta}(\mathbf{o b s}) \\
(\mathbf{d e g})\end{array}$ & $\begin{array}{c}\mathbf{2 \theta} \text { (calc) } \\
(\mathbf{d e g})\end{array}$ \\
\hline 1 & 2 & 0 & -1 & 4.59282 & 4.59479 & 19.303 & 19.294 \\
\hline 2 & 1 & 0 & -2 & 4.28883 & 4.28477 & 20.685 & 20.705 \\
\hline 3 & 1 & 1 & 1 & 3.81913 & 3.81395 & 23.263 & 23.295 \\
\hline 4 & 2 & 1 & 0 & 3.48218 & 3.48090 & 25.550 & 25.560 \\
\hline 5 & 3 & 0 & -1 & 3.13881 & 3.13725 & 28.401 & 28.415 \\
\hline 6 & 2 & 1 & -2 & 3.07372 & 3.07392 & 29.015 & 29.014 \\
\hline 7 & 2 & 1 & 1 & 2.93698 & 2.93525 & 30.398 & 30.417 \\
\hline 8 & 1 & 1 & 2 & 2.84657 & 2.84937 & 31.388 & 31.357 \\
\hline 9 & 3 & 1 & -1 & 2.73649 & 2.73839 & 32.685 & 32.662 \\
\hline 10 & 3 & 0 & 1 & 2.52323 & 2.52358 & 35.536 & 35.531 \\
\hline 11 & 1 & 2 & 1 & 2.46934 & 2.46928 & 36.338 & 36.339 \\
\hline 12 & 0 & 2 & 2 & 2.31055 & 2.31088 & 38.933 & 38.927 \\
\hline
\end{tabular}

From the X-ray powder diffraction data, the lattice parameters for XOLATU were found to be $\mathrm{a}=9.610 \AA \mathrm{,}, \mathrm{b}=5.5871 \AA$ and $\mathrm{c}=9.4249 \AA$. This is in close agreement with the values obtained from single crystal X-ray diffraction analysis for XOLATU. The change in intensity of peaks as well as addition in number of peaks for XOLATU in the powder Xray diffraction pattern reveal that the dye doped crystal is slightly distorted compared to the pure LATU. This may be attributed to strains on the lattice by the absorption or substitution of xylenol orange dye in LATU crystal.

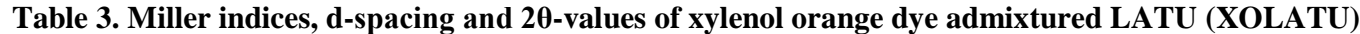
single crystal determined from powder XRD analysis using RexCell software.

\begin{tabular}{|c|c|c|c|c|c|c|c|}
\hline S. No. & $\mathbf{h}$ & $\mathbf{k}$ & $\mathbf{l}$ & $\begin{array}{c}\mathbf{d}(\mathbf{o b s}) \\
\left(\mathbf{A}^{\circ}\right)\end{array}$ & $\begin{array}{c}\mathbf{d}(\mathbf{c a l c}) \\
\left(\mathbf{A}^{\circ}\right)\end{array}$ & $\begin{array}{c}\mathbf{2 \theta}(\mathbf{o b s}) \\
(\mathbf{d e g})\end{array}$ & $\begin{array}{c}\mathbf{2 \theta} \text { (calc) } \\
(\mathbf{d e g})\end{array}$ \\
\hline 1 & 2 & 0 & -1 & 4.58479 & 4.58453 & 19.337 & 19.338 \\
\hline 2 & 2 & 0 & 0 & 4.42619 & 4.43568 & 20.037 & 19.993 \\
\hline 3 & 1 & 0 & -2 & 4.25757 & 4.25827 & 20.839 & 20.836 \\
\hline 4 & 1 & 1 & 1 & 3.81086 & 3.81316 & 23.314 & 23.300 \\
\hline 5 & 2 & 1 & 0 & 3.47989 & 3.48312 & 25.567 & 25.543 \\
\hline 6 & 3 & 0 & -1 & 3.13512 & 3.13309 & 28.435 & 28.454 \\
\hline 7 & 2 & 1 & -2 & 3.07018 & 3.06582 & 29.050 & 29.092 \\
\hline 8 & 2 & 1 & 1 & 2.93698 & 2.93443 & 30.398 & 30.425 \\
\hline 9 & 1 & 1 & 2 & 2.84355 & 2.84323 & 31.422 & 31.426 \\
\hline 10 & 3 & 1 & -1 & 2.73649 & 2.73718 & 32.685 & 32.677 \\
\hline 11 & 3 & 0 & 1 & 2.52206 & 2.52136 & 35.553 & 35.563 \\
\hline 12 & 2 & 1 & -3 & 2.46710 & 2.46885 & 36.373 & 36.346 \\
\hline 13 & 0 & 2 & 2 & 2.31055 & 2.31050 & 38.933 & 38.934 \\
\hline
\end{tabular}




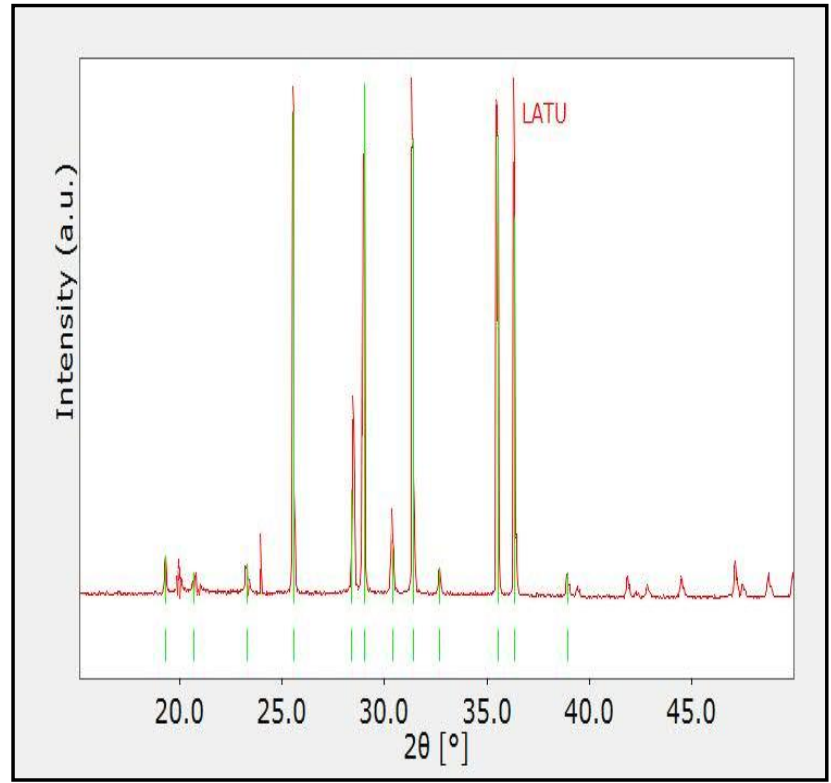

Fig. 4. PWXRD spectrum of LATU crystal

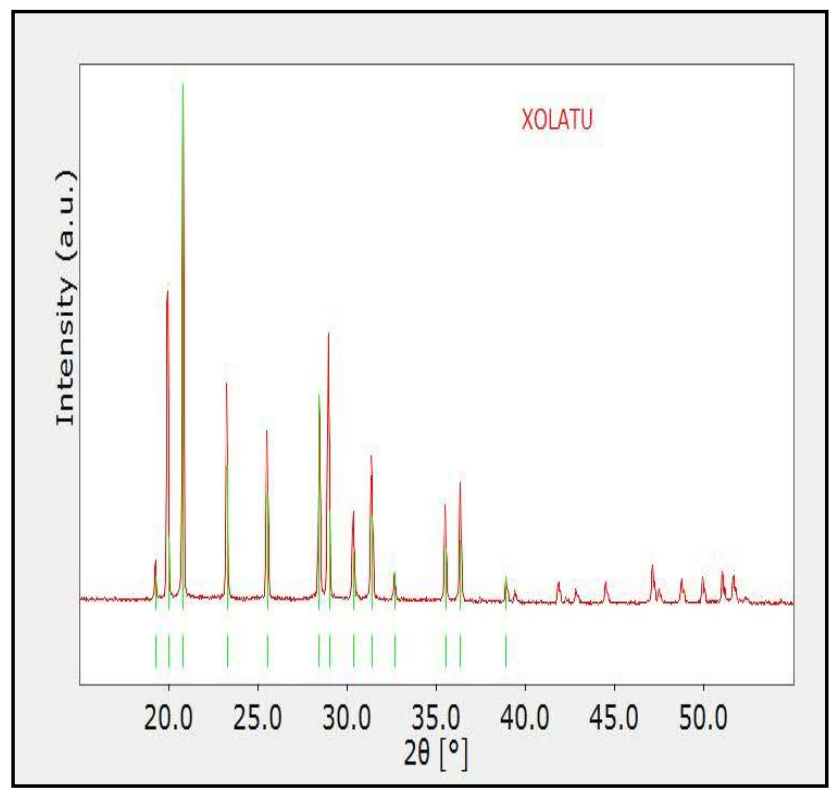

Fig.5. PWXRD spectrum of XOLATU crystal

\subsection{High Resolution X-ray Diffraction \\ Studies}

The crystalline perfection of the grown crystals were characterized by HRXRD analysis by employing a multicrystal X - ray diffractometer with $\mathrm{MoK} \alpha_{1}$ radiation designed and developed at National Physical Laboratory (NPL) New Delhi [18] has been used to record highresolution diffraction curves (DCs). The well-collimated and monochromated $\mathrm{MoK}_{1}$ beam obtained from the three monochromator $\mathrm{Si}$ crystals set in dispersive $(+,-,-)$ configuration has been used as the exploring X-ray beam. The specimen crystal is aligned in the $(+,-,-,+)$ configuration. Due to dispersive configuration, though the lattice constant of the monochromator crystal(s) and the specimen are different, the unwanted dispersion broadening in the diffraction curve (DC) of the specimen crystal is insignificant. Before recording the diffraction curve, to remove the non-crystallized solute atoms remained on the surface of the crystal and also to ensure the surface planarity, the pure LATU and xylenol orange dye admixtured LATU crystals were first lapped and chemically etched in a non-referential etchant of water and acetone mixture in 1:2 ratios [19]. Fig. 6 and Fig. 7 show the high-resolution diffraction curves (DCs) recorded for pure LATU and xylenol orange dye admixtured

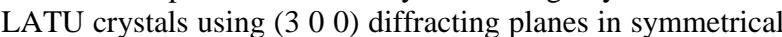
Bragg geometry by employing the multicrystal X-ray diffractometer with $\mathrm{MoK} \alpha_{1}$ radiation. The curves are very sharp having full width at half maximum (FWHM) of 14 arc sec for pure LATU and 29 arc sec for xylenol orange dye admixtured LATU crystals as expected for nearly perfect crystals from the plane wave dynamical theory of X-ray diffraction [20]. The absence of additional peaks and the very sharp DC shows that the crystalline perfection of the specimen crystals is extremely good without having any internal structural grain boundaries and mosaic nature. The increase in FWHM without having any additional peaks in DC of xylenol orange dye doped LATU crystal indicates the incorporation of xylenol orange dye in the crystalline matrix of LATU crystal. In DC of xylenol orange dye doped LATU crystal, for a particular angular deviation $(\Delta \theta)$ of glancing angle $(\theta)$ with respect to the Bragg peak position (taken as zero for the sake of convenience), the scattered intensity is much more in the positive direction in comparison to that of the negative direction.

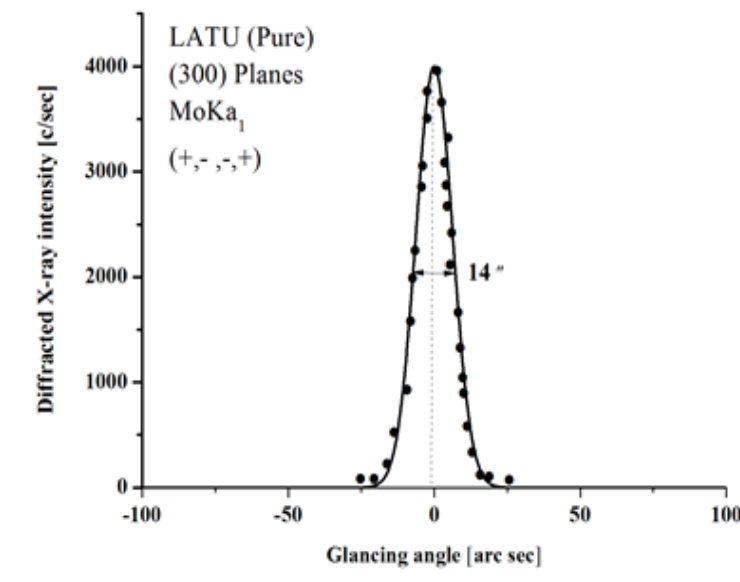

Fig. 6. HRXRD curve of pure LATU crystal

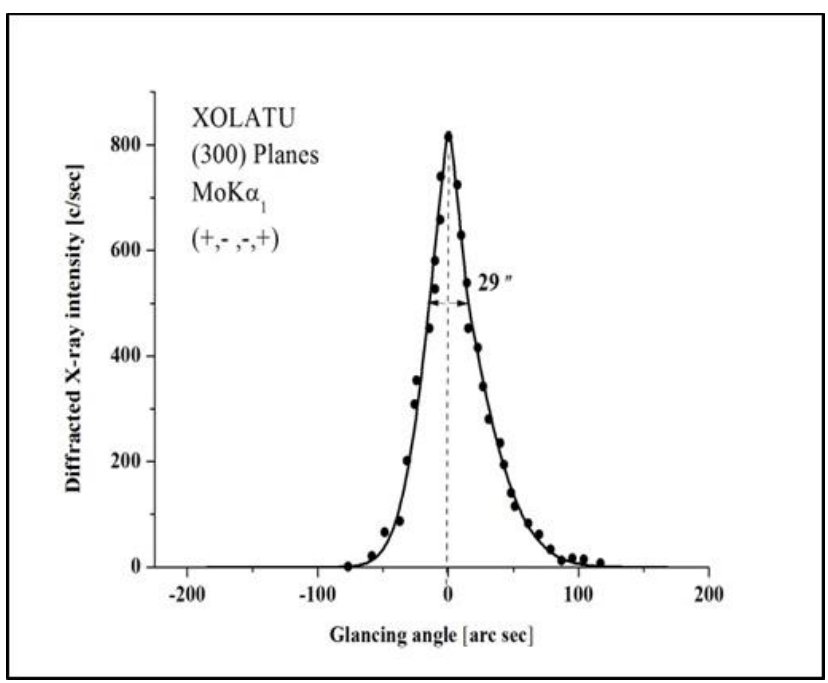

Fig. 7. HRXRD curve of XOLATU crystal 
This feature or asymmetry in the scattered intensity clearly indicates that the xylenol orange dopants predominantly occupy the interstitial positions in the lattice and elucidates the ability of accommodation of dopants in the crystalline matrix of the LATU crystal. This can be well understood by the fact that due to incorporation of dopants in the interstitial positions, the lattice around the dopants compresses and the lattice parameter $\mathrm{d}$ (interplanar spacing) decreases and leads to give more scattered (also known as diffuse X-ray scattering) intensity at slightly higher Bragg angles $\left(\theta_{\mathrm{B}}\right)$ as $\mathrm{d}$ and $\sin \theta_{\mathrm{B}}$ are inversely proportional to each other in the Bragg equation $\left(2 d \sin \theta_{B}=n \lambda ; n\right.$ and $\lambda$ being the order of reflection and wavelength respectively which are fixed). It may be mentioned here that the variation in lattice parameter is only confined very close to the defect core which gives only the scattered intensity close to the Bragg peak. Long range order could not be expected and hence change in the lattice parameter is also not expected [21]. The HRXRD results confirm an important finding that xylenol orange dye entrapped in the LATU crystals, but the amount is limited to a critical value and above which the crystals have a tendency to develop structural grain boundaries [22].

\subsection{Fourier Transform Infrared Spectroscopy}

The mid Fourier transform infrared spectrum of pure and dye doped LATU crystals were recorded at $300 \mathrm{~K}$ in the range of 4000-400 $\mathrm{cm}^{-1}$ using the $\mathrm{KBr}$ pellet technique. The FTIR spectra of pure and dye admixtured LATU crystals are shown in Fig. 8 and Fig. 9.

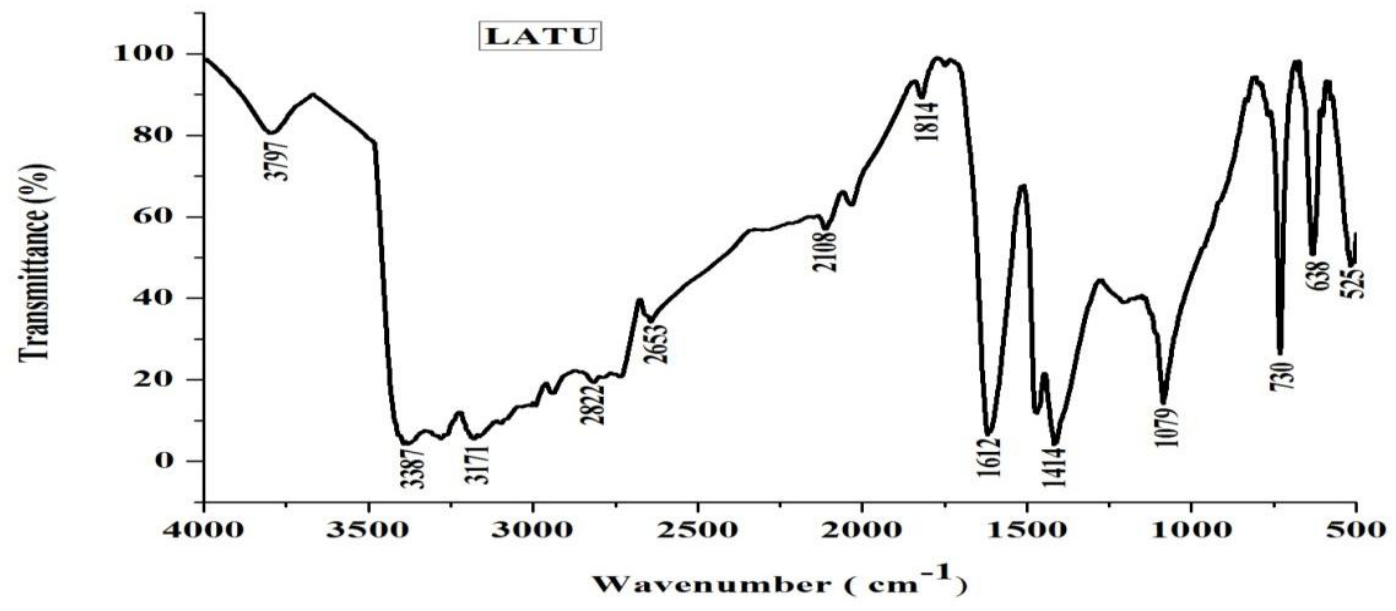

Fig. 8. FTIR spectrum of grown L-Alanine Thiourea (LATU) single crystal

The incorporation of xylenol orange dye in LATU crystal has been strongly verified by spectral analysis. In the IR-spectrum of LATU:XO crystal, the vibration connected with free $\mathrm{O}-\mathrm{H}$ stretching which is revealed at $3797 \mathrm{~cm}^{-1}$ in pure LATU is absent and this fact obviously testifies to a strong interaction between xylenol orange molecules with $\mathrm{OH}$ groups. The regions $2653 \mathrm{~cm}^{-1}, 2604 \mathrm{~cm}^{-1}$ and $738 \mathrm{~cm}^{-1}$ with strong intensity represent $\mathrm{C}-\mathrm{H}$ stretching mode. The peaks at 1414 $\mathrm{cm}^{-1}$ and $1415 \mathrm{~cm}^{-1}$ indicating the $\mathrm{C}=\mathrm{O}$ stretching mode of vibrations.

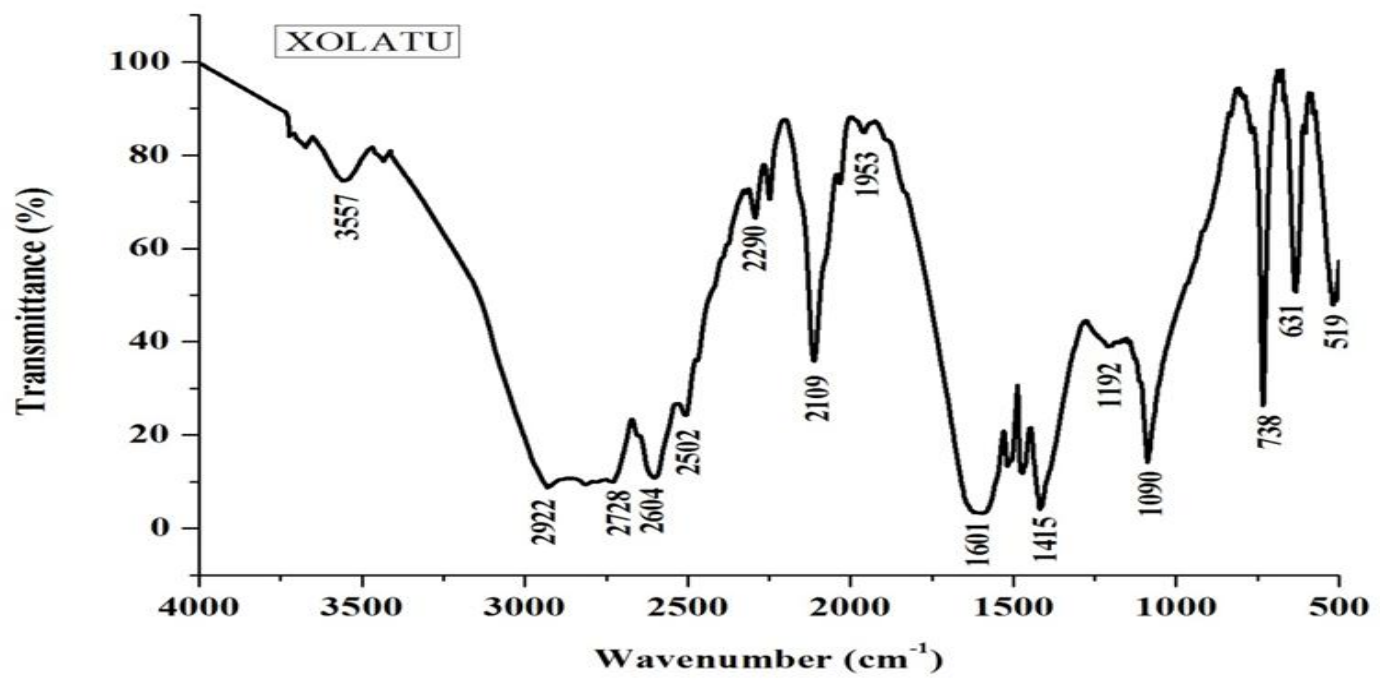

Fig. 9. FTIR spectrum of grown xylenol orange dye admixtured LATU (XOLATU) single crystal 
Table 4. Infrared absorption frequencies $\left(\mathrm{cm}^{-1}\right)$ of L-Alanine Thiourea (LATU) and xylenol orange dye admixtured LATU (XOLATU)

\begin{tabular}{|c|c|c|c|}
\hline S.No. & $\begin{array}{c}\text { L-Alanine } \\
\text { Thiourea(LATU) }\end{array}$ & $\begin{array}{c}\text { xylenol orange dye } \\
\text { admixtured } \\
\text { LATU(XOLATU) }\end{array}$ & Assignment \\
\hline 1 & 3797 & 3557 & $\mathrm{OH}$ - stretching \\
\hline 2 & 3171 & 2922 & $\mathrm{NH}_{3}{ }^{+}$symmetric stretching \\
\hline 3 & 2822 & 2723 & $=\mathrm{CH}_{2}$ stretching \\
\hline 4 & 2653 & 2604 & Aliphatic $(\mathrm{C}-\mathrm{H})$ stretch \\
\hline 5 & 2108 & 2109 & $\begin{array}{l}\text { Over tone region with a combination of symmetric } \mathrm{NH}_{3}{ }^{+} \text {bending } \\
\text { and torsional vibrations }\end{array}$ \\
\hline 6 & 1814 & 1953 & $\mathrm{C}=\mathrm{O}$ absorption \\
\hline 7 & 1612 & 1601 & $\begin{array}{l}\text { Asymmetric bending of } \mathrm{NH}_{3}{ }^{+} \text {and } \mathrm{C}=\mathrm{N} \\
\text { stretching }\end{array}$ \\
\hline 8 & 1414 & 1415 & $\mathrm{C}=\mathrm{O}$ stretching \\
\hline 9 & 1079 & 1090 & Symmetrical C-O-C stretching \\
\hline 10 & 730 & 738 & $\mathrm{C}-\mathrm{H}$ in plane bending \\
\hline 11 & 638 & 631 & $\mathrm{C}=\mathrm{S}$ stretching \\
\hline 12 & 525 & 519 & $\mathrm{~N}-\mathrm{C}-\mathrm{N}$ stretching \\
\hline
\end{tabular}

The $\mathrm{NH}_{3}{ }^{+}$asymmetric bending vibrations occur at $3171 \mathrm{~cm}^{-1}$ and at $2922 \mathrm{~cm}^{-1}$. Very strong band occurring at $525 \mathrm{~cm}^{-1}$ and $519 \mathrm{~cm}^{-1}$ is contributed by N-C-N stretching mode of vibration. The peaks at $638 \mathrm{~cm}^{-1}$ and $631 \mathrm{~cm}^{-1}$ represents C-S stretching mode of vibration. In the xylenol orange dye admixtured LATU spectrum, the $\mathrm{OH}$ stretching in the high energy region is very much broadened due to hydrogen bonding. The vibration frequencies of L-Alanine Thiourea are compared with xylenol orange dye admixtured L-Alanine Thiourea in Table 4 to confirm the incorporation of xylenol orange dye in LATU crystal.

\subsection{UV-Visible Spectral Study}

The UV-visible spectra of pure and xylenol orange dye admixtured analyses have been carried out using Shimadzu UV-visible spectrophotometer in the wavelength range of 100-1100 nm. Transmission spectra are very important for any NLO material because a nonlinear optical material can be of practical use only if it has wide transparency window [23]. The UV-visible spectra of LATU and XOLATU are shown in Fig. 10. In the case of pure LATU, a sharp fall in percent transmittance is occurred at $209 \mathrm{~nm}$. For XO admixtured LATU, the fall in percent transmittance is occurred at $310 \mathrm{~nm}$. It is followed by another percent transmittance at $295 \mathrm{~nm}$. Such variation in percent transmittance is due to electronic excitation of XO dye. It confirms that the addition of XO in the LATU crystal influence the light transmittance of LATU. In the transmission spectrum of xylenol orange admixtured LATU, the characteristic absorption of xylenol orange dye are observed at 310 and $295 \mathrm{~nm}$.

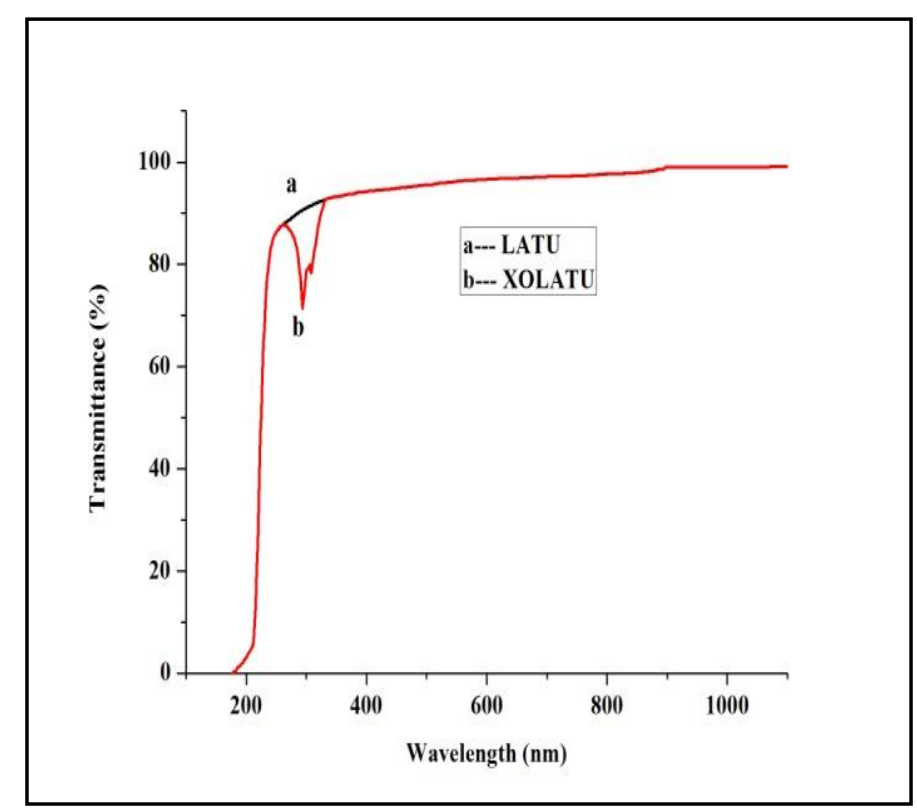

Fig. 10. UV-vis-NIR absorption spectra for LATU and XOLATU crystals 


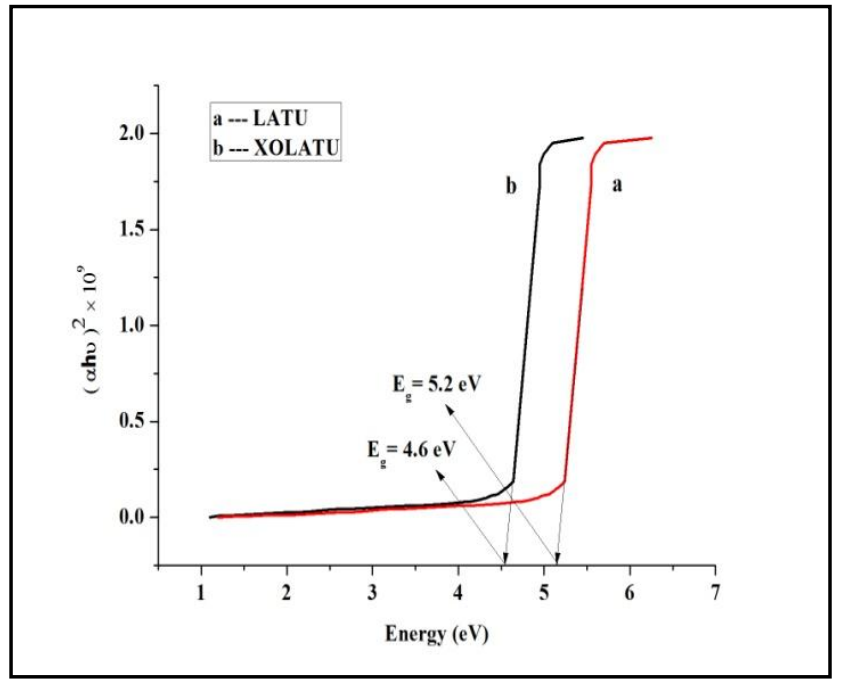

Fig. 11. Photon energy vs $(\alpha h v)^{2}$ for LATU and XOLATU crystals

\subsection{Optical Band Gap Energy $\left(E_{g}\right)$ Calculation}

The band gap energy of the pure and xylenol orange dye admixtured LATU crystals were calculated from the Fig. 11 by taking Photon energy (hv) values along $\mathrm{X}$-axis and $(\alpha \mathrm{hv})^{2}$ values along Y-axis for LATU and XOLATU crystals. The optical absorption coefficient $(\alpha)$ was calculated using the relation

$$
\alpha=(2.3026 * \log (1 / T)) / t
$$

where $\mathrm{T}$ is the transmittance and $\mathrm{t}$ is the thickness of the crystal. The band gap energy values were calculated by extrapolation of the linear part of the curve for LATU and XOLATU and found to be $5.2 \mathrm{eV}$ and $4.6 \mathrm{eV}$ respectively. The decrease in band gap energy value of dye admixtured LATU may be due to incorporation of dye in the LATU crystal lattices. The value of band gap energy for XOLATU crystal suggests that the material is dielectric in nature to possess wide transmission range. The large transmission in the entire visible region and lower cut off wavelength enable it to be a potential material for second and third harmonic generation [24].

\subsection{Thermo Gravimetric Analysis (TGA)}

Thermo Gravimetric Analysis (TGA) and Differential Thermal Analysis (DTA) were carried out for LATU and XOLATU crystals using TA Q-500 analyser. TGA and DTA curves for pure and xylenol orange dye admixtured LATU are shown in Fig. 12 and Fig. 13. The powder samples were used for the analysis in the temperature range of $0{ }^{\circ} \mathrm{C}$ to $1000{ }^{\circ} \mathrm{C}$ at a heating rate of $\quad 10{ }^{\circ} \mathrm{C} / \mathrm{min}$ in the nitrogen atmosphere. In pure LATU, the major weight loss occurs between $173.53{ }^{\circ} \mathrm{C}$ and $241.19{ }^{\circ} \mathrm{C}$. The change in weight loss confirms the decomposition nature of the sample. Differential thermal analysis confirms through a sharp endothermic peak at $217.56{ }^{\circ} \mathrm{C}$ revealing the major weight loss. Further, degradation of the sample takes place from $274{ }^{\circ} \mathrm{C}$ to $760{ }^{\circ} \mathrm{C}$ where the loss of weight is about $5.41 \%$ due to liberation of volatile substances like sulfur oxide and amino acid LAlanine [25]. The weight loss of $2.976 \%$ at the end is due to the release of $\mathrm{CO}$ molecules. Hence, it is concluded that the grown material is thermally stable up to $173.53{ }^{\circ} \mathrm{C}$.

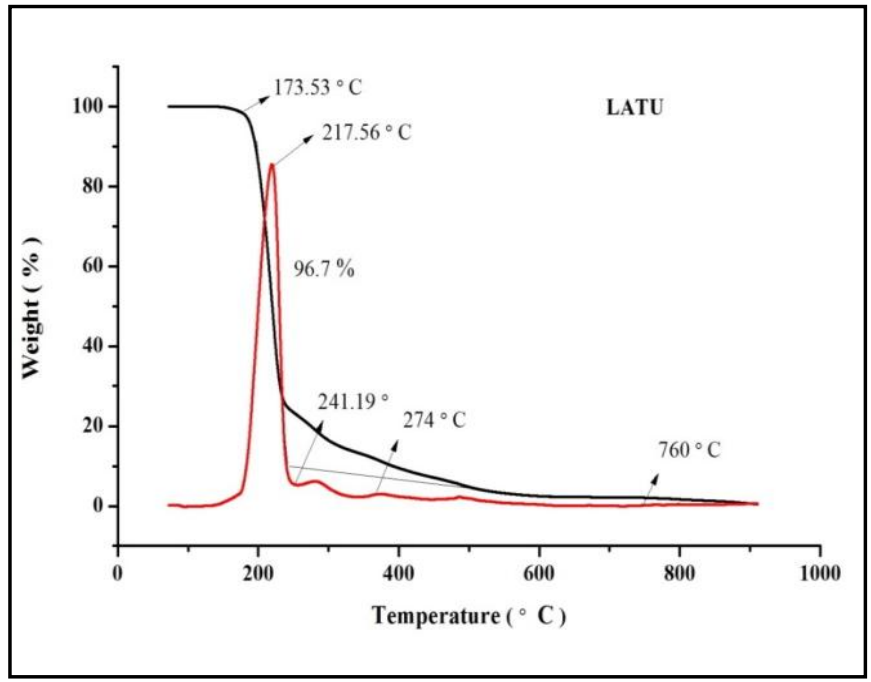

Fig. 12. TGA and DTA curves of LATU crystal

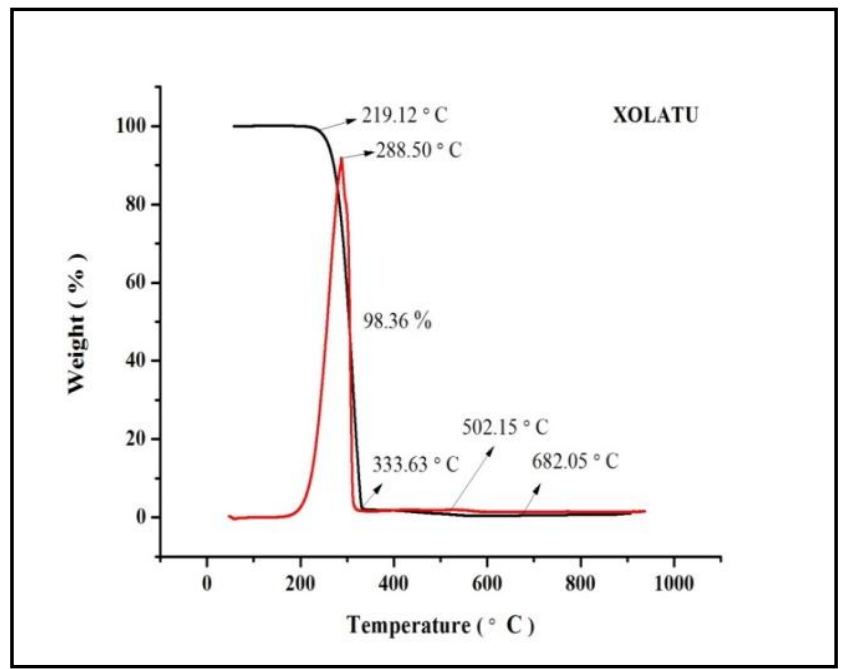

Fig. 13. TGA and DTA curves of XOLATU crystal

In xylenol orange dye admixtured LATU crystal, the major weight loss occurs between $219.12{ }^{\circ} \mathrm{C}$ and $333.63{ }^{\circ} \mathrm{C}$. The change in weight loss confirms the decomposition nature of the sample. Differential thermal analysis confirms through a sharp endothermic peak at $288.5{ }^{\circ} \mathrm{C}$ revealing the major weight loss. Further, degradation of the sample takes place from $502.15^{\circ} \mathrm{C}$ to $682.05{ }^{\circ} \mathrm{C}$ where the loss of weight is about $2.08 \%$ due to absorption of energy for breaking of bonds during the decomposition of the compound. Hence, it is concluded that the xylenol orange dye admixtured LATU crystal is suitable for optoelectronics applications up to $219.12{ }^{\circ} \mathrm{C}$.

\subsection{Dielectric Analysis}

The dielectric studies of pure LATU and xylenol orange dye admixtured LATU crystals were carried out using the HIOKI 3532-50 LCR HITESTER instrument. The capacitance values for LATU and XOLATU crystals were determined for frequencies varying from $50 \mathrm{~Hz}$ to $5 \mathrm{MHz}$ at room temperature. The variations of dielectric constant and dielectric loss as a function of log frequency are shown in Fig. 14 and Fig. 15. It is observed that the dielectric constant of pure LATU is 196 where 355 for xylenol orange dye admixtured LATU crystal. The high value of dielectric constant at low frequencies may be due to incorporation of 
xylenol orange dye in LATU in the grown crystal and better orientation of dipoles in the molecules of the crystals. The low value of dielectric loss indicates that the pure and xylenol orange dye admixtured LATU crystals have lesser defects, which is a desirable property for NLO applications.

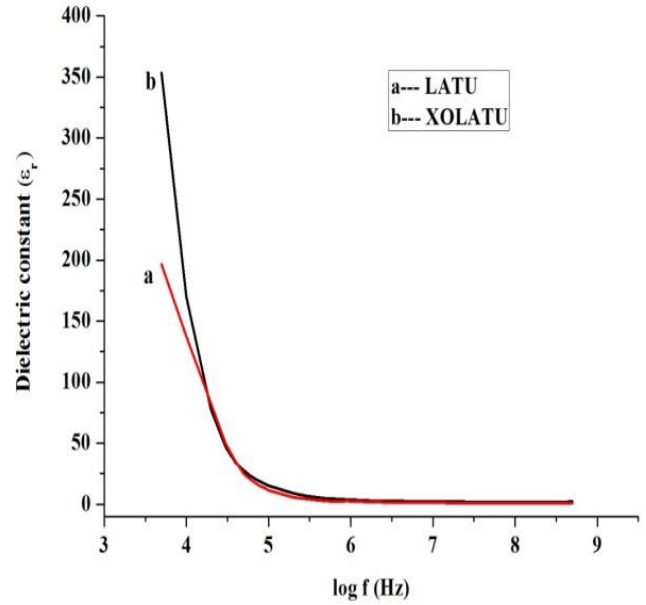

Fig. 14. Variation of dielectric constant of pure LATU and XOLATU

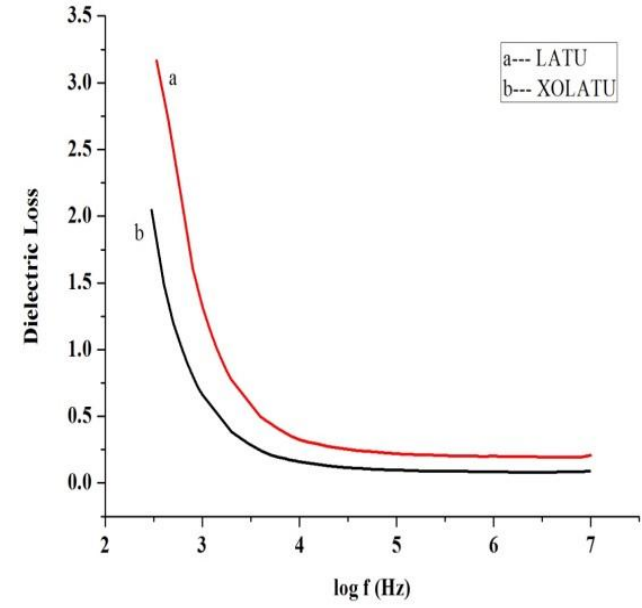

Fig. 15. Variation of dielectric loss of pure LATU and XOLATU

\subsection{Microhardness Measurements}

Microhardness behaviour of pure LATU and XOLATU single crystals were tested by using Shimadzu makemodel-HMV-2 fitted with Vickers pyramidal indenter and attached to an incident light microscope. The indentations were made on the flat surface with the load ranging from 25 to $100 \mathrm{~g}$ and the indentation time was kept as $10 \mathrm{~s}$ for all the loads. The Vickers hardness number $\mathrm{H}_{\mathrm{v}}$ was calculated from the following expression,

$$
\mathrm{H}_{\mathrm{V}}=((\mathbf{1 . 8 5 4 4} * \mathrm{P})) / \mathrm{d}^{2} \quad \mathrm{~kg} / \mathrm{mm}^{2}
$$

where $\mathrm{P}$ is the applied load in $\mathrm{kg}, \mathrm{d}$ is the diagonal length of the indentation impression in $\mathrm{mm}$ and 1.8544 is a constant of a geometrical factor for the diamond pyramid. Vickers hardness number was calculated and a graph has been plotted between the hardness values and the corresponding loads for the crystals as shown in Fig. 16. From the results, it is observed that the hardness number decreases with increasing load up to $75 \mathrm{~g}$ and attains saturation for further increase in load. Beyond this load cracks were found both in pure LATU and XOLATU single crystals. From the Fig. 16, it is observed that the microhardness value of dye admixtured crystal is slightly higher than that of the pure LATU and it is due to the presence of organic xylenol orange dye molecule in the interstitial sites of pure LATU crystal.

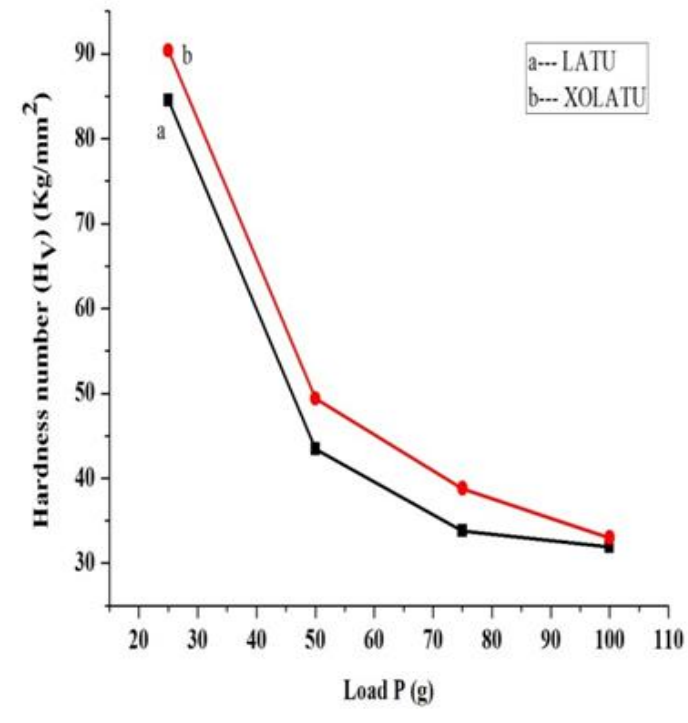

Fig. 16. Variation of hardness with applied for LATU and XO LATU single crystals

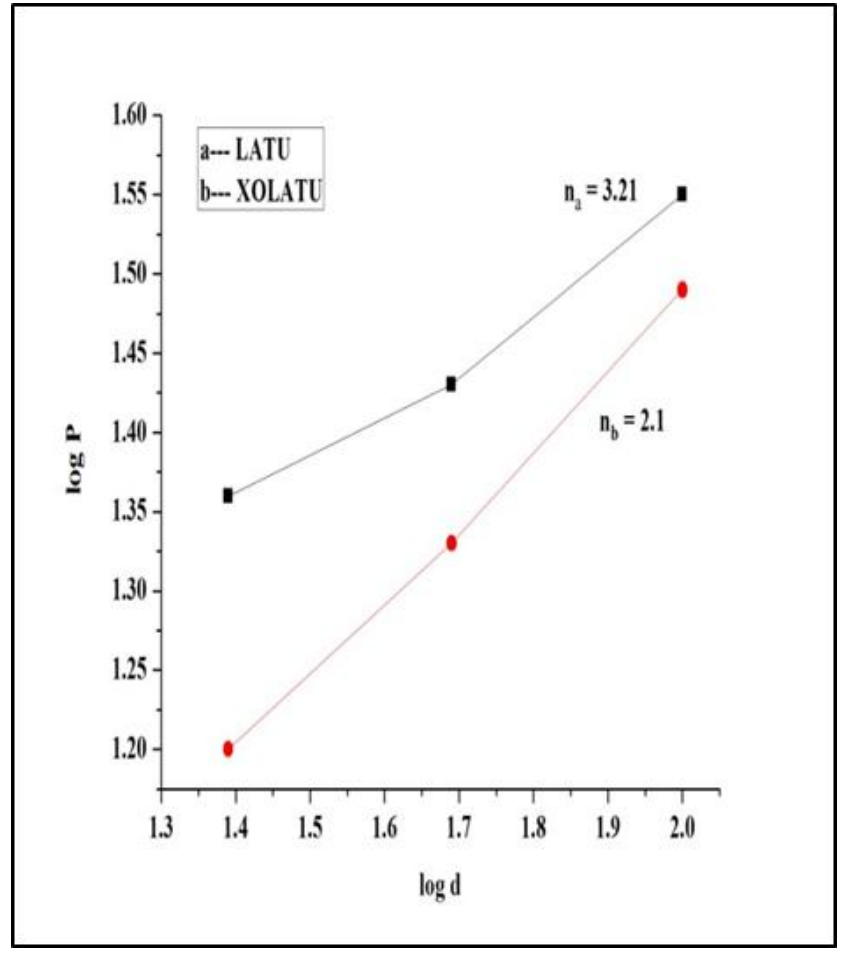

Fig. 17. Variation of $\log (\mathrm{P})$ with $\log (\mathrm{d}) \operatorname{load}$ for LATU and XOLATU single crystals 
The Mayer's index number was calculated from the Mayer's law, which relates the applied $\operatorname{load}(\mathrm{P})$ and indentation diagonal length(d).

$$
\mathbf{P}=\mathbf{a d}^{\mathbf{n}}
$$

where ' $a$ ' is the material constant and ' $n$ ' is the Mayer's index or work hardening coefficient.

The values of the work hardening coefficient (n) were estimated from the plot of $\log \mathrm{P}$ versus $\log \mathrm{d}$ drawn by the least square fit method and it is shown in Fig. 17. The work hardening coefficients (n) for pure LATU and xylenol orange dye admixtured LATU crystals were found to be 3.21 and 2.1 respectively. Onitsch [26] pointed out that ' $n$ ' lies between 1 and 1.6 for moderately hard materials and it is more than 1.6 for soft materials. The observed values of Mayer's index for LATU and XOLATU are 3.21 and 2.1 and hence they belong to the soft materials category.

\subsection{Laser Damage Threshold Studies}

The laser damage density is one of the important parameters that decide the applicability of the material for high power laser applications. The laser damage threshold values were measured using a Q-switched Nd-YAG laser source of pulse width $10 \mathrm{~ns}$ and $10 \mathrm{~Hz}$ repetition rate operating in TEM00 mode. The energy per pulse of $532 \mathrm{~nm}$ laser radiation attenuated using appropriate neutral density filters was measured using an energy meter (Coherent EPM 200) which is externally triggered by the $\mathrm{Nd}$ :YAG laser. If the material has a low damage threshold, it severely limits its application, though it may have excellent properties like high optical transmittance and high SHG efficiency [27]. For surface damage, the sample was placed at the focus of a plano-convex lens of focal length $30 \mathrm{~cm}$. The (100) plane of pure and dye admixtured crystals was used for the laser damage studies. The surface threshold of the crystal was calculated using the expression:

$$
\text { Power density }(\mathbf{P d})=\mathrm{E} / \tau \pi \mathrm{r}^{2}
$$

Where $E$ is the energy $(\mathrm{mJ}), \tau$ is the pulse width (ns) and $r$ is the radius of the spot $(\mathrm{mm})$. The measured multiple shot $(150$ pulses) laser damage threshold values of pure and dye admixtured LATU crystals are 9 and $7.8 \mathrm{GW} / \mathrm{cm}^{2}$ respectively. The decrease in laser damage threshold value of dye admixtured LATU may be due to incorporation of dye in the LATU crystals

\subsection{NLO Studies}

Nonlinear optical (NLO) property of pure L-Alanine Thiourea (LATU) and xylenol orange dye admixtured LATU crystals were determined by Kurtz powder technique using the Nd:YAG Q-switched laser beam. The samples of same sizes were illuminated using Q-switched, mode locked Nd:YAG laser with input pulse of $6.2 \mathrm{~mJ}$. The second harmonic signals of $384 \mathrm{mV}$ and $630 \mathrm{mV}$ were obtained for pure and xylenol orange dye admixtured LATU crystals with reference to KDP $(275 \mathrm{mV})$. Thus, the SHG efficiency of LATU and xylenol orange dye admixtured LATU crystals was found to be 1.39 and 2.29 times greater than the standard KDP crystal. The relative SHG efficiency of xylenol admixtured LATU crystal was found to be 1.64 times higher than that of pure LATU crystal.

\section{CONCLUSION}

Good quality of LATU and xylenol orange dye admixtured LATU crystals were grown by slow evaporation method. The unit cell parameters of the crystals obtained from single crystal XRD showed that the LATU and XOLATU crystals belong to monoclinic system with space group $\mathrm{P} 2_{1}$. Sharp peaks of powder XRD pattern of the crystals confirm the good crystalline nature of the grown crystals and the incorporation of xylenol orange dye into LATU crystal lattice. The functional groups of XOLATU crystal were identified by FTIR spectral analysis and they have confirmed the presence of organic additive xylenol orange dye in LATU crystal. The UV-vis-NIR transmittance spectra showed that the crystals had a wide optical window and the absorption due to xylenol orange dye in LATU crystal. The optical band gap energy values of LATU and XOLATU crystals are found to be 5.2 $\mathrm{eV}$ and $4.6 \mathrm{eV}$ respectively. The decrease in band gap energy value of dye admixtured LATU may be due to incorporation of dye in the LATU crystal lattices. The addition of xylenol orange dye in LATU crystal increased the thermal stability of pure LATU crystal. The sharpness of the endothermic peak shows good degree of crystallinity of the crystal. The Vickers micro hardness values were calculated in order to understand the mechanical stability of the crystals. Dielectric studies for the crystal were studied. NLO studies have confirmed that the SHG efficiency value was significantly enhanced due to the presence of xylenol orange dye in LATU crystal.

\section{ACKNOWLEDGMENTS}

The authors thank Dr. G. Bhagavannarayana, NPL, New Delhi, for HRXRD studies. The authors express thanks to SAIF, IIT Madras Chennai for providing the spectral analysis.

\section{REFERENCES}

[1] J.F. Nicoud, R.J. Twieg, 1987, "Nonlinear Optical Properties of Organic Molecules and Crystals", Eds. D.S. Chemla and J. Academic Press, London, pp 227-296.

[2] E. Gallegos-Loya, E. Orrantia-Borunda, A. DuarteMoller, M. Delfino, 1979, "An Optical Overview of Poly[ $\mu 2$-L-alanine- $\mu 3$-nitrato-sodium (I)] Crystals" The Scientific World Journal, 52, 271.

[3] J.D. Bernal, Z. Kristallogr. 1931, 78, 363.

[4] H.J. Simpson Jr., R.E. Marsh, 1966, Acta Cryst. 8, 550.

[5] R. Destro, R.E. Marsh, R. Bianchi, 1988, Journal of Physical Chemistry, 92, 966.

[6] N. Zaitseva, L. Carman, 2001, "Rapid growth of KDPtype crystals", Prog. Crystal Growth and Charact, vol. 43, pp. 1-118.

[7] P. Angeli Mary, S. Dhanuskodi, 2001, Cryst. Res. Technol., 36, 1231 .

[8] H.K. Hellwege, A.M. Hellwege, 1982, "LandoltBornstein: Numerical Data and Functional Relationship in Science and Technology Group II", Springer, Berlin, pp. 584-586.

[9] S. Alfred Cecil Raj, 2013, "Growth, Spectral, Optical and Thermal characterization of NLO Organic Crystal Glycine Thiourea", International Journal of Chem Tech Research, vol.5, pp. 482-490.

[10] S. Nalini Jayanthi, A. R. Prabhakaran, D. Subashini, 2013, "Growth and characterization of a Non-Linear Optical crystal: Thiourea added L-Histidine crystals", International Journal of Advances in Engineering \& Technology, vol.5, pp. 85-92.

[11] R. Kannan, D. Jayaraman, S. Aravindhan, 2014, 
"Enhancement of SHG, Spectral, Optical, Thermal, Dielectric and Mechanical Properties of Methylene Blue Admixtured L-Alanine Thiourea Single Crystal", Chemical Science Review and Letters, vol. 3, pp. 22786783.

[12] Yu., Velikhov, 2007, "Growth and properties of dyed KDP crystals" Cryst. Res. Technol., vol. 42, pp. 27-33.

[13] J.B. Benedict, P.M. Wallace, P.J. Reid, S.H. Jang, B. Kahr, 2003, Advanced Materials, vol. 15, pp. 1068-1070.

[14] Mohammad Nasiruddin Khan, Sadaf Bhutto, 2009, "Kinetic Study of the Oxidative Decolorization of Xylenol Orange by Hydrogen”, J. Chil. Chem. Soc., 55, pp. 170-175.

[15] Vogel I, 1961, A Text Book of Quantitative Inorganic Analysis, 3rd edn ( London, Logman Green \& Co. Ltd. ), 428.

[16] S. Palanisamy, O. N. Balasundaram, 2008, "Growth, Optical and Mechanical Properties of Alanine Sodium Nitrate (ASN)", Rasayan Journal of Chemistry, vol. 1, pp. 782-787.

[17] K. Lal, G. Bhagavannarayana, 1989, “A high-resolution diffuse X-ray scattering study of defects in dislocation free silicon crystals grown by the float-zone method and comparison with Czochralski-grown crystals", J. Appl. Cryst., vol. 22, pp. 209- 215.

[18] S.K. Kushwaha, M. Shakir, K.K. Maurya, A. L. Shah, M.A. Wahab, G. Bhagavannarayana, 2014, "Remarkable enhancement in crystalline perfection, Second Harmonic Generation Efficiency, Optical Transparency and laser damage threshold in KDP crystals by L-threonine doping", Cornell University Library, arXiv:1403.4869.

[19] B.W. Batterman, H. Cole, 1964, "Dynamic diffraction of
X-rays by perfect crystals”, Rev. Mod. Phys., vol. 36, pp. 681-717.

[20] G. Bhagavannarayana, S.K. Kushwaha, M. Shakir, K.K. Maurya, 2010, J. Appl. Crystallogr., vol. 44, pp. 122128

[21] G. Bhagavannarayana, S.K Kushwaha, 2010 , "Enhancement of SHG efficiency by urea doping in ZTS single crystals and its correlation with crystalline perfection as revealed by Kurtz powder and highresolution X-ray diffraction methods", J. Appl. Crystallogr., vol. 43, pp. 154-162.

[22] P. Anandan, R. Jayavel, T. Saravanan, G. Parthipan, C. Vedhi, R. Mohan Kumar, 2012 , "Crystal growth and characterization of L-histidine hydrochloride monohydrate semi organic nonlinear optical single crystals", Optical Materials, vol. 30, pp. 1225-1230.

[23] J. Ramajothi, S. Dhanuskodi, 2007, "Crystal growth, thermal and optical studies on a semiorganic nonlinear optical material for blue-green laser generation", Spectrochimica Acta part A, vol. 68, pp. 1213-1219.

[24] N.R. Dhumane, S.S. Hussaini, Kunal Datta, Prasanta ghosh and Mahendra, D.Shirsat, 2010, J. Pure Appl. \& Ind. Phys., vol. 1, pp. 45-52.

[25] E.M. Onitsch, 1956 , "The present status of testing the hardness of materials", Mikroskopie. Vol. 95, pp. 12-14.

[26] D. Kalaiselvi, R. Mohan Kumar, R. Jayavel, 2008, "Growth and Characterization of nonlinear optical Larginine maleate dehydrate single crystals", Materials Letters, 61, 755-758.

[27] H. Nakatani, W.R. Bosenberg, L.K. Cheng, C.L. Tang, 1988, Appl. Phys. Lett. 53, 2587-2589. 